\title{
Voltammetric Determination of Nitrophenol using PEDOT Decorated Graphene Oxide as Composite Film
}

\author{
Nafiu Muhammad ${ }^{1,3}$, Jaafar Abdullah ${ }^{1,2, *}$, Yusran Sulaiman ${ }^{1,2}$, Lim Hong Ngee ${ }^{1,2}$ \\ ${ }^{1}$ Department of Chemistry, Faculty of Science, Universiti Putra Malaysia, 43400 UPM Serdang, \\ Selangor DarulEhsan, Malaysia \\ ${ }^{2}$ Institute of Advanced Technology, Universiti Putra Malaysia, 43400 UPM Serdang, Selangor D.E., \\ Malaysia. \\ ${ }^{3}$ Department of Pure and Industrial Chemistry, Faculty Natural and Applied Sciences,Umaru Musa \\ University Yar'aduaKatsina, PMB 2218, Katsina state Nigeria \\ *E-mail: jafar@upm.edu.my
}

doi: $10.20964 / 2017.10 .68$

Received: 16 June 2017 / Accepted: 10 August 2017 / Published: 12 September 2017

A composite film of poly(3,4-ethylenedioxythiophene) (PEDOT) and reduced graphene oxide (ERGO) deposited on screen printed carbon electrode (SPCE) was developed for the sensitive detection of 3nitrophenol(NP). The electrode was modified with PEDOT/ERGO by using electropolymerization technique on the surface of SPCE. This new hybrid sensing material exhibits high electrocatalytic activity and good selectivity towards the reduction of 3-NP due to its excellent electrical conductivity, strong adsorptive ability and large effective surface area of PEDOT/ERGO composite film. The enhancement factor of the PEDOT/ERGO modified SPCE towards 3-NP was calculated to be 4 times higher compared to bare SPCE. Experimental parameters such as $\mathrm{pH}$ of buffer, scan rate, accumulation time and accumulation potential were optimized. Under optimum experimental conditions, the linear calibration curve of the sensor towards concentration of 3-NP was in the range of $0.3 \mu \mathrm{M}$ to $70 \mu \mathrm{M}$ with the detection limit of $0.08 \mu \mathrm{M}$. Furthermore, the PEDOT/ERGO sensor shows good repeatability and reproducibility with relative standard deviation (RSD) of $3.83 \%$ and $4.85 \%$, respectively. The sensor also demonstrated potential application for the detection of 3-NP in water samples.

Keywords: PEDOT; ERGO; sensing material; nitrophenol; environment

\section{$\underline{\text { FULL TEXT }}$}

(C) 2017 The Authors. Published by ESG (www.electrochemsci.org). This article is an open access article distributed under the terms and conditions of the Creative Commons Attribution license (http://creativecommons.org/licenses/by/4.0/). 